\title{
REFLEXIONES EN TORNO A LA ARGUMENTACIÓN DESDE LA PERSPECTIVA ARISTOTÉLICA
}

\author{
REFLECTIONS ON ARGUMENTATION \\ FROM THE ARISTOTELIAN PERSPECTIVE
}

B ajo el numeral Imitación y argumentación poética del libro Teorías aristotélicas del discurso de Luis Xavier López Farjeat (2002), el autor se propone mostrar el discurso argumentativo que encierra la poética en sus múltiples expresiones.

Se reconoce desde un principio el carácter imitativo de los géneros de la poética que corresponden a dos: arte y experiencia. El primero, a la trasformación del artefacto y el segundo, al hábito. López Farjeat propone que el proceso argumentativo en la poética dependerá de una "lógica informal" que recurre a la retórica y que guarda estrechas relaciones con las acciones humanas. El hecho de que la función de la poética sea la imitación implica que el imitador debe saber a quien imita imprimiéndole, en este caso, un profundo sentido ético a la imitación.

El imitador puede hacer una copia mejor o peor sobre el sujeto original que copia. Este procedimiento, en cuanto a la imitación, se asocia al oficio del historiador, en cuanto, él es quien puede por medio de su narrativa engrandecer u opacar ciertos hechos o personajes históricos. Incluso puede imprimirle cierta sujetividad y emotividad al relato histórico. Desde el lenguaje se establece la estructuración adecuada de los hechos, de tal manera que sean ordenados e inteligibles por medio de las palabras. Este procedimiento refleja una tipo particular de argumentación que para el caso de la historia sería una "lógica histórica". De este modo, el autor indica algunos aspectos importantes con relación a la argumentación: 1 . El argumento depende de la unidad de la narración, 2. Hay argumentos mal construidos como los relatos episódicos, 3. Se distinguen dos tipos de argumentos: uno el simple que es aquel que tiene un desarrollo continuo; y segundo el complejo que va acompañado de reconocimiento y 4. Las partes de un argumento son: la peripecia y el reconocimiento.

En este Vol. 6 \# 1 - 2019 (enero-junio) se publican doce artículos de investigación y revisión que dan cuenta de sólidos procesos de argumentación desde la temática desarrollada y que aportan de manera significativa a la construcción de conocimiento en el campo de la inclusión social y el desarrollo social. Los artículos son:

Dueñas Gaitán

Editor de la Revista

Inclusión y Desarrollo

Corporación Universitaria

Minuto de Dios - UNIMINUTO inclusionydesarrollo@uniminuto.edu

1. "Paz y convivencia escolar: Una experiencia en Ciudad Bolívar", donde se describe la información con respecto a la cátedra de la paz que manejan estudiantes y docentes de un colegio de Ciudad 
Bolívar en Bogotá, Colombia, a través de las características de instrumentos para evaluar la convivencia escolar de los estudiantes del plantel educativo y los conocimientos de los docentes y los estudiantes para establecer el impacto de la formación de paz en la convivencia educativa.

2. "Relaciones entre el rol del docente y la equidad en educación superior", presenta una postura crítica y propositiva acerca de la relación entre el rol del docente y el logro de la equidad en educación superior, como una agenda importante en Colombia y la región. Inicia con una aproximación general a los conceptos e indicadores de la equidad en educación superior desde una perspectiva de género y enfoque ético-profesional. Posteriormente, analiza los desafíos del rol del docente en aspectos como las pretensiones de la calidad educativa, el contexto social y la discriminación durante el proceso enseñanza-evaluación.

3. "Innovación disruptiva, estrategia de inclusión al emprendimiento social", analiza los procesos de innovación disruptiva como una estrategia de inclusión hacia el emprendimiento social; en cuanto al desarrollo metodológico, se realizó una revisión documental de forma sistemática en bases indexadas, con el fin de consultar e identificar información pertinente y de interés en la recopilación y construcción de los referentes teóricos.

4. "Las implicaciones de las políticas públicas en los ámbitos de intervención de las mujeres campesinas en el contexto neoliberal mexicano", reflexiona sobre las políticas públicas sociales, de tipo productivo y comunitario dirigidas a la sociedad campesina pero con impacto mayor en los ámbitos de desarrollo de las mujeres campesinas de México.

5. "Consecuencia de la inobservancia del término de duración del proceso artículo 121 del C.G.P.”, trata de la inclusión social desde la perspectiva del acceso a la justicia, cuando se acude a los juzgados en busca de la reivindicación de derechos.

6. "NeuroArte un programa de fortalecimiento de las funciones ejecutivas en niños con TDAH", se determina el efecto de un programa de estimulación neurocognitivo musical sobre las Funciones Ejecutivas (FE) de niños colombianos diagnosticados con TDAH.

7. "La enseñanza diferenciada e integradora en la economía del conocimiento", se describe que la educación es el factor más influyente en el progreso equitativo de los pueblos, lo cual exige que la enseñanza que se imparte induzca a la persona a un aprendizaje que genere habilidades y destrezas basado en principios y valores, para que comprenda y aplique el conocimiento en correspondencia con las exigencias del mercado laboral de tal forma que pueda contribuir al desarrollo socioeconómico de esta sociedad.

8. "Estrategias pedagógicas para desarrollar la dimensión comunicativa en preescolar", tiene como propósito analizar cómo el docente de transición de un jardín público de Bogotá, hace uso de 
estrategias pedagógicas en sus clases para estimular el desarrollo de la dimensión comunicativa, a través de un aprendizaje significativo, que sea transferible a su realidad.

9. "Importancia del extensionismo rural en la Ciudad de México (CDMX)", analiza diversos componentes que participaron en el proyecto que se conoce como Apoyo al Extensionismo Rural, Desarrollo de Capacidades y Asociatividad Productiva de la SAGARPA y que se compartió en el año 2016, 2017 y 2018 junto con el Gobierno de la CDMX por medio de la SEDEREC.

10. "Relación de los movimientos oculares sacádicos y la comprensión lectora con el déficit de atención e hiperactividad (TDAH)", establece una posible relación entre el TDAH, la calidad de los movimientos sacádicos y la comprensión lectora en niños de 7 a 12 años con y sin déficit de atención e hiperactividad.

11. "Reflexión en torno a la perspectiva del currículo y las aulas virtuales", da a conocer la importancia que tiene la reflexión del currículo por competencias y la virtualidad dentro de las comunidades académicas, desde allí se describen los diferentes paradigmas y concepciones que tienen los maestros y que desarrollan dentro de sus prácticas educativas en los diferentes escenarios educativos donde laboran.

12. "El riesgo de la lectura literaria en el aula: abrirse a los mundos que los jóvenes sueñan", centra su atención en la lectura literaria como subjetividad política. Los sujetos involucrados en este estudio son lectores jóvenes entre dieciséis y veintiún años de la IED La floresta Sur en Bogotá

\section{Referencia bibliográfica}

